\title{
Perception of the Effects of Substance Abuse among University Students: A Case of Built Environment and Civil Engineering Students at a South African University in Gauteng Province
}

\author{
*Justus N. Agumba, I. Musonda \\ University of Johannesburg, South Africa \\ *jagumba@uj.ac.za
}

\begin{abstract}
Substance abuse among youths is a worldwide epidemic that impacts negatively on the health sector as well as the family and society. Early student life at the university is a time of tremendous high motivation to conform to the behaviours, values and attitudes that are valued by the student culture. However, students observe their peers' behaviour and alter their own behaviour with their peers' norms and expectations. Some of the perceived peer norms can however lead to substance abuse, which has led students' not to complete their education. Therefore, the main aim of this study was to determine students' perception on the effects of substance abuse on their physical, cognitive and affective development. The research philosophy adopted was positivism and the approach was deductive. Hence, a self-administered questionnaire containing items developed from literature review was administered to 199 built environment and civil engineering students at a South African university. The data was analyzed using the Statistical Package for the Social Sciences (SPSS) version 21. The reliability for internal consistency of the measured constructs i.e. physical, cognitive and affective was determined using Cronbach's alpha test. Independent sample t-test was used to test the hypotheses on the perception of students who had experimented on drugs and those who had not experimented on drugs on their physical, cognitive and affective development. The results suggest that over 40 percent of students in this university are not aware of the substance abuse policy. Furthermore there was no statistical significant difference on the perception of the effect of substance abuse on students who had experimented on drugs and those who had not experimented on drugs on their physical and affective development. However, there was a significant difference on the effect on their cognitive development. It is recommended that students at this university should be made aware of the substance abuse policy. Furthermore, those who experimented on substances e.g. drugs indicated less perception on their effects on their cognitive development. It is recommended that this cohort of students warrants further research.
\end{abstract}

Keywords: Built Environment, Effects, Engineering, Perception, Students

\section{Introduction}

It is probably uncontroversial to state that all university campuses struggle with containing and controlling alcohol and drugs consumption by their students, this was highlighted in a discussion with the vice chancellor and members of staff of this university being researched (Vice-Chancellor university campus visit, 2014). This sentiment is supported by the study of Dlamini et al. (2012) which inferred that alcohol is still freely available on campus. Substance abuse could be exacerbated with the age at which students first enter such institutions. An age of freedom and experimentation, where young students have the opportunity to test the limits previously set by parents and schools. Parents expect a university to provide a nurturing environment for their children which would be conducive to studying. It is expected that a university should provide a safe, enriching and rewarding educational experience for a student. This will ensure that students would develop their social and intellectual skills without any hindrances. However, recent news reports about South African university campuses have led to speculation about the safety of students on campus (Flanagan, 2011). According to Towl (2004) alcohol consumption has been described as a core component of student culture and is seen as a defining feature of tertiary education lifestyle. Alcohol is among the most abused substances in South Africa. Furthermore, substance indulgence has prompted students to lose focus on their primary reason for embarking on a study in higher education. 
Students normally enter university to further their studies and acquire knowledge so they can improve their chances of entering the job market. Students' fees are a substantial expense for parents and guardians especially when no bursaries are secured. Students aspire to obtain qualifications which would equip them with skills to follow noble career paths. These students would expect to have a positive experience that will contribute towards successfully completing their studies. Many students believe that higher education is a genuine place for one to enjoy academic bliss. Aside from the high colour paraphernalia and sophisticated digital media used for promoting students enrolments, students need to understand that university is another community within which advantages and disadvantages exist. Every university in South Africa faces challenges and students ought to be aware of these challenges. Students should not be deceived into thinking that they have entered an ideal educational environment which is free from the influences of drugs and alcohol abuse and similar vices (Dlamini et al., 2012). According to Botvin et al. (1990) some students who have experimented on substances such as tobacco, alcohol eventuates in compulsive patterns of use characterized by psychological and physical dependence. This paper examines students' awareness of substance abuse policy and their perception of effect of substance abuse on their physical, cognitive and affective development.

Creating a substance abuse free environment: The ambience of a "watering hole" is entirely different from that of a library or learning centre. Any attempts to merge these two environments would be a certain recipe for disaster. Universities need to take a firm stand to ensure that such calamities are prevented. According to the Shellenbarger (2011), survey conducted in Purdue University showed a sharp drop in drinking among students from $48 \%$ in 2006 to $37.3 \%$ in 2009 . Much of this success is attributed to a new trend in alcohol free events on or around campus grounds. According to the Higher Education Centre (2011) a comprehensive approach has been developed to assist students with alcohol use, which addresses the issues not only through educational channels but also by bringing about change at the institutional, community, and public policy level. The premise of this approach is grounded in the principle that people's attitudes, decisions, and behaviour and those that relate to alcohol use are shaped by the physical, social, economic, and legal environments. This Centre argues that many aspects of this environment can be shaped by campus and government officials. This model, termed environmental management, has since been supported by scientific research for its effectiveness in bringing about lasting and positive change on a college campus.

Environmental management: According to the Higher Education Centre (2011), environmental management addresses several factors that, though they may vary in the degree to which they exist on a college campus, have significant effects on students' decisions regarding alcohol use. These factors are:

- Students' lack (or lack of awareness of) adequate social, recreational, and extracurricular options to deter them from drinking;

- Students' perception of a strong normative pressure to drink in college;

- College students are often the targets of aggressive marketing and promotion tactics by the alcohol industry;

- Alcohol is often abundantly available on and around college campuses; and

- Campus and local laws and policies on alcohol can be vague or non-existent and are not always consistently or adequately enforced.

The Higher Education Centre (2011) states that in order to further the target and address these factors, a strategy driven approach has been devised which should be adapted to each campus needs and problems. The following are some suggestions:

- To offer and promote social, recreational, extracurricular, and public service alcohol-free options which will be integral to avoiding the promotion of alcohol within the campus grounds. To create a social, academic, and residential environment that supports health-promoting norms that would help sustain the initiative to assist students who consume alcohol on campus;

- To restrict marketing and promotion of alcoholic beverages both on and off campus as this will reduce the temptation to consume alcohol;

- To limit alcohol availability both on and off campus which would help remove the element of convenience in purchasing or obtaining alcohol;

- To further develop campus policies and enforce laws at campus, local, state, and national levels; and 
- In order to drive this effort forward, it is recommended that the university body measure the extent of the problem as well as the nature of the problem and not ignore the factors that propel the use and consumption of alcohol on campus.

The effects of substance abuse: The effects of substance abuse on the development of tertiary students can occur in the following areas:

- Their physical development; and

- Psychological development i.e. cognitive and affective development.

Physical development: Physical development of a person concerns the growth of the body. This entails changes in the proportions between different parts of the body and changes in the internal structure and functioning of the body (Gouws \& Kruger, 2003; Vrey, 1996).

Effects of substance abuse on physical development: Substance abuse has, amongst other, the effects on the physical development of the student. Smoking drugs such as marijuana causes various respiratory problems and diseases such as daily coughing, acute chest illness and risk of lung infections (National Institute on Drug Abuse, (NIDA, 2014; South African National Council for Alcohol and Drug Dependence (Sanca, 2004). Furthermore, smoking can aggravate asthma and prevent enough oxygen and nutrients from nourishing the skin, giving rise to bad skin and a disease called psoriasis (Life scope, 2004). Furthermore, continued smoking causes breakdown of lung tissue and clogging of the air sacs (Izenberg and Lyness, 2002). Based on the aforementioned discussion the researchers infer that student will be less active in sports performance. The student will suffer from increased heartbeat, poor blood circulation and shortness of breath making it difficult for him to engage in activities that students of his age group engage in. Drug abuse may make the student giddy, stagger, lose balance and will affect his motor co-ordination (Sanca, 2004). Motor dysfunction (especially dysfunction regarding fine motor co-ordination as required for articulation, writing and eye movements) may cause students to experience speaking, writing and reading difficulties (Jeram, 2009). Substance abuse robs the body of essential vitamins and minerals and interferes with the digestion of food (Sanca, 2004).

Psychological development: Psychological development refers to the development of mental characteristic or attitude of a person with specific emphasis on those factors affecting behaviour in a given context (Allen, 1993). The psychological development of the student will be discussed by distinguishing between the cognitive and affective aspects.

Cognitive development: The term cognitive development refers to the continuous and cumulative development of the intellect and has to do with thinking skills, creatively, perception, conceptualization, insight, knowledge, imagination and intuition (Jeram, 2009). According to Du Toit and Kruger (1994) and Vrey (1996) secondary school learners display different characteristics during their cognitive development. The authors believe that these characteristics will also be experienced by university students. The student will have a conscious focus on the world and acquires knowledge of the world in a cognitive and formal manner. They acquire further new skills in calculation of mathematics, physics and also incorporate new concepts in his knowledge structure. Furthermore, the student is expected to remember information and apply the information when solving problems and be able to reproduce it a later stage. The student can communicate effectively and his vocabulary is large enough to follow teaching. Perceptually, the student can assign meaning to sensation and can recognize, memorize, integrate, differentiate and imagine. The student learns by personal experience and by active participation. His attention span improves and he is able to concentrate for longer periods. The student is capable of devoting himself seriously to his tasks and completing them properly. Furthermore the student is willing, eager and ready to learn (Jeram, 2009).

Effects of substance abuse on cognitive development: Substance abuse can affect the cognitive development of the students in the following ways:

Substance abuse interferes with a good nutrient supply to the brain and may result in brain damage, which is done in a cognitive and formal manner. Excessive alcohol use causes the brain to age prematurely. Brain disorders commonly associated with alcoholism are Weenicke's Syndrome, Koraskoff's Psychosis and 
Marchiafava's Disease (Bezuidenhout, 2004). The use of addictive substance over a long period of time may impair the memory and problem solving abilities of the student (NIDA, 2014). This has serious consequence on academic achievement as well as appropriate life decisions that a student has to make.

Furthermore, it erodes the self-discipline necessary for learning. The student may experience problems with reading, calculating, writing and incorporating new concepts into his knowledge structure. Ultimately, the student may experience falling grades and may drop out of school (Jeram, 2009). The student who abuse alcohol finds it more difficult to be cautious and to use good judgment to protect him/herself. They find it more difficult to think clearly because the more they drink, the more slowly their brain works (Lifescope, 2004). This in turn can lead to difficulty in reading, calculating and writing skills. Marijuana smoking may result in the loss of short-term memory and impairs a person's ability to learn and concentrate, which in turn affects his problem solving abilities and the ability to reproduce information at a later stage. The marijuana user experiences a lack of initiative, motivation and concern about the future (Ravesafe, 2003).

Affective development: The affective development is an emotional development concerned with emotions, feelings, passion, moods, sentiments and whims and determines the students' personality (Van den Aardweg and Van den Aardweg, 1990). The students emotions are aroused by internal rather that external factors. The student shows a greater understanding for the feelings of others and simultaneously displays a greater degree of empathy and sympathy. They also express, control, suppress or hide emotions according to social rules thus meeting the requirements of his cultural groups, his peer group and his community. The students express aggression (anger, rage, stubbornness) becomes more refined and he/she uses the social skills that he/she has acquired to cope, i.e., communication and co-operation. Anger and rage make him moody and he/she will sometimes tend to use force to solve his/her problems or relieve his frustrations (Jeram, 2009). Happiness and cheerfulness is expressed within the confines of his peer group to which he constantly strives to be accepted. The student often prefers to gloat at a friend's defeat rather than express happiness outwardly for social reasons. They understand moods and mood changes and the positive and negative feelings with which they leave him. Furthermore the student learns to suppress his emotions leading to stress, depression, feelings of discontent and bad moods. They also learn to rid themselves of unpleasant feelings by having a good cry, doing rigorous exercise or having a good laugh (Jeram, 2009).

Effects of substance abuse on affective development: The following are some of the effects that substance abuse may possibly have on the affective development of the students: Alcohol intake can lead one being talkative and friendly or aggressive and angry. It can also alter emotions, movement, vision and hearing. In addition to this it can make people do embarrassing things like throwing up or urinating on themselves (Rutherford, 2004). Furthermore, alcohol intake causes a student to become more angry and stubborn or get into a rage without much provocation. The student has not learnt to express control, suppress or hide his emotions in line with expectation of his peer group, his cultural group and his community. Substance abuse can weaken a person's inhibitions, dull the common sense, bring out sexually aggressive behaviour and make the student more egocentric (Rodgers, 2011). Students sometimes attempt to hide feelings and emotions by abusing substances. The "high" that the substance abuser experiences can be a very happy or "spaced out" feeling or a feeling that he has special powers like the ability to fly or get rid of all his problems (Brown, 2004). Since substance abuse has interfered with the students' ability to suppress his emotions, the student may display anger, rage, stubbornness and jealousy in an open and less refined manner (Jeram, 2009).

Marijuana use has been noted for blunting emotions and for making the student paranoid. The student will most probably end up becoming suspicious and fearful of the people around him causing him to bed-wet, stammer, boast, be anxious or engage in noisy behaviour, which are symptoms of suppressed fear (Bowman, 2002). Jealousy may be displayed by anger, rage and the use of force rather than by teasing, lying and bullying. Substance abuse and addiction may cause stress and anxiety, which in turn may cause the user to increase the substance dosage to cope with the situation. When this fails, the individual may suffer from uncontrolled depression and may commit suicide (Rodgers, 2011). Once the student becomes psychologically dependent on drugs and alcohol they find it difficult to stop. Bezuidenhout, (2004) inferred that $90 \%$ will experience some degree of relapse. Even if the student wishes to stop they will not know how to because they have relied on substance abuse to resolve problems and escape from the reality. The student may become less co-operative, less friendly and less sensitive to others who may want to assist him. 
Problem statement: It has been indicated that substance abuse is rampant among university students in South Africa. This could lead to health problems of the students and poor performance in their studies. The purpose of this research was to determine the effects of substance abuse among university students and further determine their awareness of substance abuse policy of the university. In order to achieve the purpose of the research the following research questions were set:

- What is the awareness of substance abuse policy among the university students?

- What are the perception of the effect of substance abuse among university students who have experimented on the substance and those who have not experimented on the substance pertaining to their physical, cognitive and affective development?

The following specific objectives were set:

- To determine the awareness of substance abuse policy among the university students; and

- To determine their perception of the effects of substance abuse among students who have experimented on the substance and those who have not

Furthermore, the following hypotheses were tested:

- (H1) There is no significant difference on the perception of the effect of substance abuse on physical development between the students who have experimented on the substances and those who have not experimented on the substances;

- (H2) There is no significant difference on the perception of the effect of substance abuse on cognitive development between the students who have experimented on the substances and those who have not experimented on the substances; and

- (H3) There is no significant difference on the perception of the effect of substance abuse on affective development between the students who have experimented on the substances and those who have not experimented on the substances.

\section{Methodology}

The research philosophy of the study was positivism and adopting a deductive approach. Based on the research philosophy and approach adopted in this study the review led to the identification 23 items measuring three constructs i.e. physical, cognitive and affective depicting the effect of substance abuse on students. The use of structured questionnaire survey in an in-depth exploration of the constructs underlying the subject matter of the research was used. Creswell (1994) describes a survey as a quantitative or numeric description of some fraction of the population - the sample, which enables researchers to generalize their findings from a sample of respondents to a population within the limitations of the sampling method. A purposive sample was used where the researchers selected sample members to conform to some or other criterion in this case university students. The respondents were reading for the qualifications on Baccalaureus Technologiae (BTech) Civil Engineering, Construction Management or Quantity Surveying programs. Furthermore, those who were reading for National Diploma in Civil Engineering and Building were also included. A total of 199 usable questionnaires were gathered of which 51 were reading for National Diploma in Civil Engineering, 137 pursing National Diploma in Building and 11 were reading for BTech in Construction Management, Quantity Surveying and Civil Engineering. This sample size was sufficient to meet the statistical test requirements for group statistical testing. As part of the delimitation process (Creswell, 1994) of this research, few respondents reading for BTech in quantity surveying, civil and construction management did not complete the questionnaire. This limits the generalization of the sample.

Purposive sampling is a non-probability method of sampling it is impossible to evaluate the extent to which such samples are representative of the relevant population (Welman \& Kruger, 2001). In some respects purposive sampling gives the research qualities of a case study (Creswell, 1994). These problems with generalizing from the sample to the whole population of built environment and civil engineering students are limitations of the research design and fully acknowledged in this research. The questionnaire surveys were administered under controlled lecture room conditions to ensure the standardization of data gathering, to decrease non-response errors and to increase response rates (Cooper \& Schindler, 1998). The data was 
gathered using self-administered questionnaires (Leedy, 1997). Furthermore, as the questionnaires were completed anonymously, the collection of the data and the presentation of this report cannot harm the respondents or their organization in any way. The need for content validity was not established as no, pilot study and pre-testing was done on the questionnaire. The structured questions were analyzed using the Statistical Package for the Social Sciences (SPSS) version 21. This resulted in the computation of frequencies, parametric statistics in the form of independent sample t-test to test the hypotheses set. The reliability for internal consistency of the constructs of physical, cognitive and affective development was determined using Cronbach's alpha test (Cooper \& Schindler, 1998). Hair et al. (2006) advocated for a cut-off value of 0.70 and above as sufficient in achieving internal consistency of a construct. This cut-off value was adopted for this present study.

\section{Results and discussion}

The result in Table 1 indicates that majority, i.e. slightly over $61 \%$ of students were male and $38 \%$ were female. This is an indication that gender transformation is taking place in the faculty of the built environment and engineering. It can be indicated that this particular university is adhering to the South Africa government policy of allowing female to purse built environment and engineering qualification. Furthermore majority of the students were Blacks (92.0\%), Whites (5.0\%), Indians (1.5\%) and Coloureds (1.5\%). As per the qualification the students were pursuing $25.6 \%$ were reading for National Diploma in Civil Engineering, $68.8 \%$ pursing National Diploma in Building and 5.5\% were reading for Baccalaureus Technologiae (BTech) in Construction Management, BTech Quantity Surveying and BTech Civil Engineering.

Table 1: Demography of the respondents

\begin{tabular}{lll}
\hline Gender & Frequency & Percentage \\
\hline Female & 75 & 38.1 \\
Male & 122 & 61.9 \\
& & \\
Race & 183 & 92.0 \\
African/blacks & 3 & 1.5 \\
Coloured & 3 & 1.5 \\
Indian & 10 & 5.0 \\
White & & \\
& & \\
Qualification registered for & 51 & 25.6 \\
National diploma civil & 137 & 68.8 \\
National diploma building & 4 & 2.0 \\
BTech construction management & 5 & 2.5 \\
BTech quantity surveying & 2 & 1.0 \\
BTech civil engineering & & \\
\hline
\end{tabular}

The result in Table 2 indicated that slightly over 40 percent of students in this university are not aware of the substance abuse policy in the university. This might be the reason why students are using drugs and abusing substance in the campus.

Table 2: Awareness of the university substance abuse policy

\begin{tabular}{lll}
\hline Awareness & Frequency & Percentage \\
\hline Yes & 79 & 40.1 \\
No & 118 & 59.9 \\
\hline
\end{tabular}

The result in Table 3 indicates that the physical development construct was measured using six items. The combined reliability for internal consistency of the construct physical development was above the required cut-off of 0.70 at 0.86 advocated by Hair et al., (2006). This is an indication that the measures (items) for physical development are reliable and can be reused in other similar studies. An independent sample t-test was conducted to compare the physical development scores of students who have experimented on substances and those who have not experimented on substance i.e. drugs etc. There was significant difference 
in scores for students who have experimented on drugs $(M=3.17, S D=1.08)$ and those who have not experimented on drugs $(\mathrm{M}=3.56, \mathrm{SD}=1.00, \mathrm{t}(168)=-2.24, \mathrm{p}=0.03$, two tailed). Therefore, rejecting the null hypothesis (H1) stated and accepting the alternative hypothesis. Those who had not experimented on the substance perceived that the effect of substance abuse on physical development was significant than those who had experimented on the substances. The groups mean score was 3.17 and 3.56 respectively. Those who had experimented on the substances e.g. drugs might be in denial that drugs affected their physical development.

The result in Table 3 further indicates that the cognitive development construct was measured using eight items. The combined reliability for internal consistency of the construct cognitive development was above the required cut-off of 0.70 at 0.9 advocated by Hair et al., (2006). This is an indication that the measures (items) for physical development are reliable and can be reused in other similar studies. Furthermore, an independent sample t-test was conducted to compare the cognitive development scores of students who have experimented on drugs and those who have not experimented on drugs. There was no significant difference in the mean scores for students who had experimented on drugs $(M=3.24, S D=1.05)$ and those who had not experimented on drugs $(\mathrm{M}=3.43, \mathrm{SD}=0.88 ; \mathrm{t}(123.02)=-1.20, \mathrm{p}=0.23$, two tailed $)$ as the $\mathrm{p}$-value was greater than 0.05 . Therefore, accepting the null hypothesis (H2) stated. This is an indication that the effect of substance abuse on cognitive development of the students was not different. However, the groups mean score was 3.24 and 3.43 respectively. The mean scores indicated that the students were neutral on the effects of substance abuse on their cognitive development.

Table 3: Perception of students who have experimented on drugs and those who have not experimented on drugs on the effects on the physical, cognitive and affective development

\begin{tabular}{|c|c|c|c|}
\hline \multicolumn{2}{|c|}{ Variable: Physical development $\quad$ Items $=6$} & \multicolumn{2}{|c|}{ Cronbach alpha $=\mathbf{0 . 8 6}$} \\
\hline Variable & Levene test of equality of variances & $t$-value & Sig. $(p)$ \\
\hline Physical development & 0.22 & -2.24 & 0.03 \\
\hline \multicolumn{2}{|c|}{ Variable: Cognitive development $\quad$ Items $=8$} & \multicolumn{2}{|c|}{ Cronbach alpha $=0.91$} \\
\hline Variable & Levene test of equality of variances & $t$-value & Sig. $(p)$ \\
\hline Cognitive development & 0.02 & -1.20 & 0.23 \\
\hline \multicolumn{2}{|c|}{ Variable: Affective development $\quad$ Items $=9$} & \multicolumn{2}{|c|}{ Cronbach alpha $=0.92$} \\
\hline Variable & Levene test for equality of variances & $t$-values & Sig. $(p)$ \\
\hline Affective development & 0.01 & -3.53 & 0.001 \\
\hline
\end{tabular}

Finally, the result in Table 3 indicates that the affective development construct was measured using nine items. The combined reliability for internal consistency of the construct physical development was above the required cut-off of 0.70 at 0.92 advocated by Hair et al., (2006). This is an indication that the measures (items) for cognitive development are reliable and can be reused in other similar studies. An independent sample t-test was conducted to compare the affective development scores of students who have experimented on drugs and those who have not experimented on drugs. There was significant difference in scores for students who have experimented on drugs $(\mathrm{M}=2.88, \mathrm{SD}=1.07)$ and those who have not experimented on drugs $(\mathrm{M}=3.41, \mathrm{SD}=0.80 ; \mathrm{t}(131.31)=-3.53, \mathrm{p}=0.001$, two tailed). Therefore, rejecting the null hypothesis (H3) stated and accepting the alternative hypothesis. Those who had not experimented on drugs perceived that the effect of substance abuse on their affective development was significant than those who had experimented on drugs as the groups mean score was 2.88 and 3.41 respectively. Those who had experimented on the substances might be in denial that the substances they used did not affect their affective development.

\section{Conclusion}

The students at this university should be made aware of the substance abuse policy which would assist them to understand the repercussion of their health when they abuse the substances e.g. drugs, alcohol etc. Furthermore, those who experimented on the substances indicated less perception on the effects of the substance on their cognitive development compared with those who had not experimented on the substances. This needs to be investigated further using interviews with the students. 


\section{References}

Allen, R. E. (1993). The concise Oxford dictionary of current English. Delhi: Rekha Printers.

Bezuidenhout, T. J. (2004). A reader on selected social issues: Pretoria: Van Schaik Publishers.

Botvin, J. G., Baker, E., Dusenbury, L., Tortu, S. \& Botvin, M. E. (1990). Preventing adolescent drugs abuse through a multimodal cognitive-behavioral approach: Results of a 3-year study. Journal of Consulting and Clinical Psychology, 58(4), 437-446.

Bowman, W. (2002). Teen's health and drugs: what you should know. http://www.kidshealth.org/PageManager.sp?dn=Kidshealth\&lic=18PS=207\&catid=2014 accessed $05 / 03 / 2014$

Brown, T. (2004). Understanding the psychological effects of street drugs. http://www.mind.org..../understanding+the+sychological+effects+of+street+drugs.ht.Accessed $01 / 03 / 2014$

Cooper, D. R. \& Schindler, P. S. (1998). Business research methods. Boston: McGraw Hill.

Creswell, J. W. (1994). Research design, qualitative and quantitative approaches. London: Sage.

Dlamini, J. B., Rugbeer, H., Naidoo, G. M., Metso, R. M. \& Moodley, P. (2012). The effects of alcohol consumption on student life at rural campus. Inkanyiso Journal of Human and Social Sciences, 4(1), 49-57

Du Toit, S. J. \& Kruger, N. (1994). The child: an educational perspective: Durban: Butterworth.

Flanagan, L. (2011). What makes protests turn violent? IOL News. http://www.iol.co.za/news/southafrica/gauteng/what-makesprotests-turn-violent-1.1102375 Accessed 03/03/2014

Gouws, E. \& Kruger, N. (2003). The adolescent: an educational perspective. Johannnesburg: Heinemann.

Hair, J. F., Black, W. C., Babin, J. B., Anderson, R. E. \& Tatham, R.L. (2006). Multivariate data analysis, $6^{\text {th }}$ Edition. Upper Saddle River, New Jersey: Pearson/Prentice Hall.

Higher Education Centre. (2011). Addressing Alcohol Use on Campus. http://www.higheredcenter.org/highrisk/alcohol/addressing Accessed 10/03/2014

Izenberg, N. \& Lyness, D. (2002). Kid's health - date rape: what you should know? http://kidshealth.org/Pagemanager.jsp?dn=Kidshealth\&Lic Accessed 03/03/2014

Jeram, H. R. (2009). Substance abuse amongst secondary school learners. Unpublished Masters Dissertation University of Zululand

Leedy, P. D. (1997). Practical Research: Planning and Design. Sixth Edition Published by Prentice-Hall, Inc. Simon and Schuster/A Viacom Company, Upper Saddle River, New Jersey, USA.

Lifescope. (2004). Children and drugs: part 2. http://www.lifescope.Com/pages/How2s/Drug Child_2.html. Accessed 15/03/2014

Rodgers, K. (2011). Health and disease in society; substance use and abuse $1^{\text {st }}$ edition Published by Britannica Educational Publishing in association with Rosen Educational Services, LLC 29 East 21st Street, New York, NY 10010.

Rutherford, K. (2004). Kid's health: dealing with addiction http://www.kidshealth.org/kid/grow/drugs_alcohol/alcohol_P2.html Accessed 20/03/2014

Shellenbarger, S. (2011). College Parties minus the Beer Binges. Wall Street Journal, http://online.wsj.com/article/SB10001424052748703312904576146232117046602.html Accessed 11/03/2014

South African National Council for Alcohol and Drug Dependence (Sanca). (2004). Everything you always wanted to know about alcohol and other drugs. Durban: Printermaster.

Towl, D. (2004). Alcohol Use and Tertiary Students in Aotearoa - New Zealand. ALAC Occasional Publication, 21, 1-40.

Van den Aardweg, E. M. \& Van den Aardweg, E. D. (1990). Dictionary of Empirical Education / Educational Psychology. Pretoria: E \& E Enterprises.

Very, J. D. (1996). The self-actualizing education. Pretoria: University of South Africa.

Welman, J. C. \& Kruger, S. J. (2001). Research methodology. Cape Town: Oxford. 